\title{
Mechanical performances of elastomers used in diffusers
}

This article was published in the following Dove Press journal:

Medical Devices: Evidence and Research

I3 June 201 I

Number of times this article has been viewed

\author{
Gérard Guiffant ${ }^{\prime}$ \\ Jean-Jacques Durussel' \\ Patrice Flaud' \\ Jean-Pierre Vigier' \\ Christian Dupont ${ }^{2}$ \\ Philippe Bourget ${ }^{3}$ \\ Jacques Merckx' \\ 'University Paris Diderot, Paris, \\ France; ${ }^{2}$ University Teaching Hospital \\ Cochin, Paris, France; ${ }^{3}$ University \\ Teaching Hospital Necker-Enfants \\ Malades, Paris, France
}

\begin{abstract}
The use of elastomeric diffusers (EDs) has grown together with the expansion of home care. In these devices, the fill volume of the drug reservoir and the flow rate are preset and cannot be modified. The elastomer, which makes up the reservoir walls, is what makes the infusate flow due to the pressure it exerts. The purpose of this work was to quantify, under standardized experimental conditions and following recommended conditions of use, the mechanical performances of the 2 commonly used elastomers (silicone and polyisoprene) and their impact on infusion flow rate consistency. Results show that they exhibit different mechanical performances which leads to concerns regarding the use of these devices for some intravenous (IV) therapies.
\end{abstract}

Keywords: elastomeric diffusers, perfusion, drug administration rate, infusion flow, infusion devices

\section{Introduction}

Portable diffusers are nonimplantable, sterile, single use, nonprogrammable pumps. They function without an external source of energy and by a gravity independent mechanism. ${ }^{1,2}$ They take up little space, are light and preserve patient mobility. They have no maintenance costs and are without risk of presenting an erroneous flow rate. Among them, diffusers with a balloon (reservoir) or elastomeric diffusers (EDs) are the most common. Their use is increasing, together with the increased prevalence of home care in various therapeutic fields (oncology, antibiotherapy, peripheral nerve block analgesia), as well as with the search for greater patient comfort and autonomy. Their efficiency in administering various therapies has been documented, ${ }^{3-9}$ as well as their level of performance, which has been questioned. ${ }^{10-12}$

A major ED specification is the flow rate. In volumetric and syringe-pumps, the flow rate is set by the operator. The electric motor maintains it by exerting pressure on a syringe plunger for example, which varies according to fluid path resistance. EDs function differently. The elastomer, which makes up the reservoir walls, is what causes the flow, through the pressure $(\mathrm{P})$ it exerts on the IV fluid. The difference between the pressure $(\mathrm{P} \approx 380 \mathrm{mmHg})$ and the venous pressure $\mathrm{P}_{\mathrm{v}}$ allows the infusate to flow out of the reservoir. It does so through a calibrated capillary hydraulic resistance $\left(R_{h}\right)$ which is set into the proximal or distal end of a flexible tube tied to one end of the reservoir (Figure 1). These 3 parameters $\left(\mathrm{P}, \mathrm{P}_{\mathrm{v}}\right.$, and $\left.\mathrm{R}_{\mathrm{h}}\right)$ interact to give the flow rate $(\mathrm{Q})$ as per the following formula: $\mathrm{Q}=\left(\mathrm{P}-\mathrm{P}_{\mathrm{v}}\right) / \mathrm{R}_{\mathrm{h}}{ }^{13}$ This tells us that $\mathrm{Q}$ cannot be constant if $\mathrm{P}$ changes. When in use, as the reservoir empties, its volume decreases, which directly impacts the stress forces on the elastomer. Therefore, its mechanical performances
Correspondence: Gérard Guiffant Université Paris Diderot, MSC, UMR CNRS 7057, 10 rue Alice Domon et Léonie Duquet, 75205 Paris, cedex 13, France

Tel +33015727704 I

$\mathrm{Fax}+3301572762$ II

Email gerard.guiffant@univ-paris-diderot.fr 


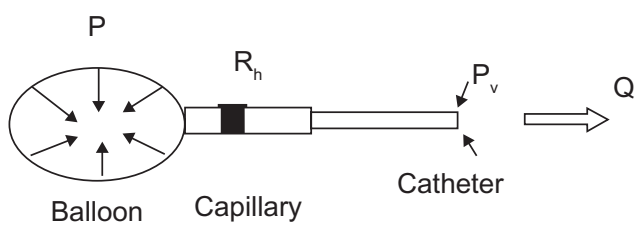

Figure I Schematic representation of the ED working principle.

are of crucial importance in maintaining constant pressure during the infusion period.

The purpose of this work was to quantify, under standardized experimental conditions, the mechanical performances of 2 commonly used elastomers (silicone and polyisoprene) and their impact on infusion flow rate regularity.

\section{Material and methods}

The two types of elastomer tested were: a silicone ( $\mathrm{Si}$ ) inorganic polymer and a polyisoprene $(\mathrm{Pi})$ material close to natural rubber. In the absence of a reference liquid, ${ }^{13}$ distilled water was chosen to fill the reservoirs. The experimental setup is shown Figure 2. The elastomeric reservoirs were taken from unused, commercially available EDs. They were fastened at each extremity to a tube (length $85 \mathrm{~mm}$, internal diameter $10 \mathrm{~mm}$ ) similar to commercial devices. Through a bypass, the reservoir's internal pressures $(\mathrm{P})$ were registered by a sensor (KOBOLD type SEN 8600, Kobold Instruments Inc, Pittsburgh, PA) linked to an AUF 1000screen (Tetra Tec Instruments GmbH, Steinenbronn, Germany) at every $5 \mathrm{~mL}$ of fluid infused. The recorded values are the difference between the atmospheric pressure and $\mathrm{P}$. The flow rate was deduced from the weight of the distilled water, in grams $(\mathrm{g})$, recovered during the infusion. The mass was recorded every 30 seconds by scales (Mettler Toledo PB3002-SDR, MettlerToledo Inc, Columbus, $\mathrm{OH}$ ) linked to a computer.

For each type of elastomer, we performed enough tests $(\mathrm{N}>4)$ to ensure result reproducibility. In the first part of the tests, the reservoirs were filled to $100 \mathrm{~mL}$ as recommended by the manufacturers. The claimed flow rate was $200 \mathrm{~mL} /$ hour. In the second part, the Si reservoirs were filled to 200 or $300 \mathrm{~mL}$, the Pi ones to 240 and $300 \mathrm{~mL}$, as recommended by their manufacturers. The claimed flow rates were $5 \mathrm{~mL} /$ hour for the $200 \mathrm{~mL}$ Si reservoirs and the $240 \mathrm{~mL}$ Pi ones and $10 \mathrm{~mL} /$ hour for the other 2 models.

We also performed the tests applying various counter pressures, $\mathrm{P}_{\mathrm{v}}$, to simulate physiological and pathological venous pressure. Physiological venous pressure $\mathrm{P}_{\mathrm{v}}$ at rest ranges between 3 and $6 \mathrm{~mm} \mathrm{Hg}\left(4-8 \mathrm{~cm} \mathrm{H}_{2} \mathrm{O}\right)$, however, it can reach much higher values in some instances (eg, coughing fits, or cardiac insufficiency). Results for $\mathrm{P}_{\mathrm{v}}$ of $3 \mathrm{~mm}$ and $44 \mathrm{~mm} \mathrm{Hg}\left(60 \mathrm{~cm} \mathrm{H}_{2} \mathrm{O}\right)$ are reported in Figures 4 and 5. Lastly, we introduced a time delay of 12 hours between fill time and infusion duration.

\section{Results}

a. Pi and Si reservoirs filled to nominal volume, flow rate of $200 \mathrm{~mL} /$ hour, $\mathrm{P}=380 \mathrm{~mm} \mathrm{Hg}$, low $\mathrm{P}_{\mathrm{v}}(3 \mathrm{~mm} \mathrm{Hg})$. Reservoir internal pressure results are summarized in

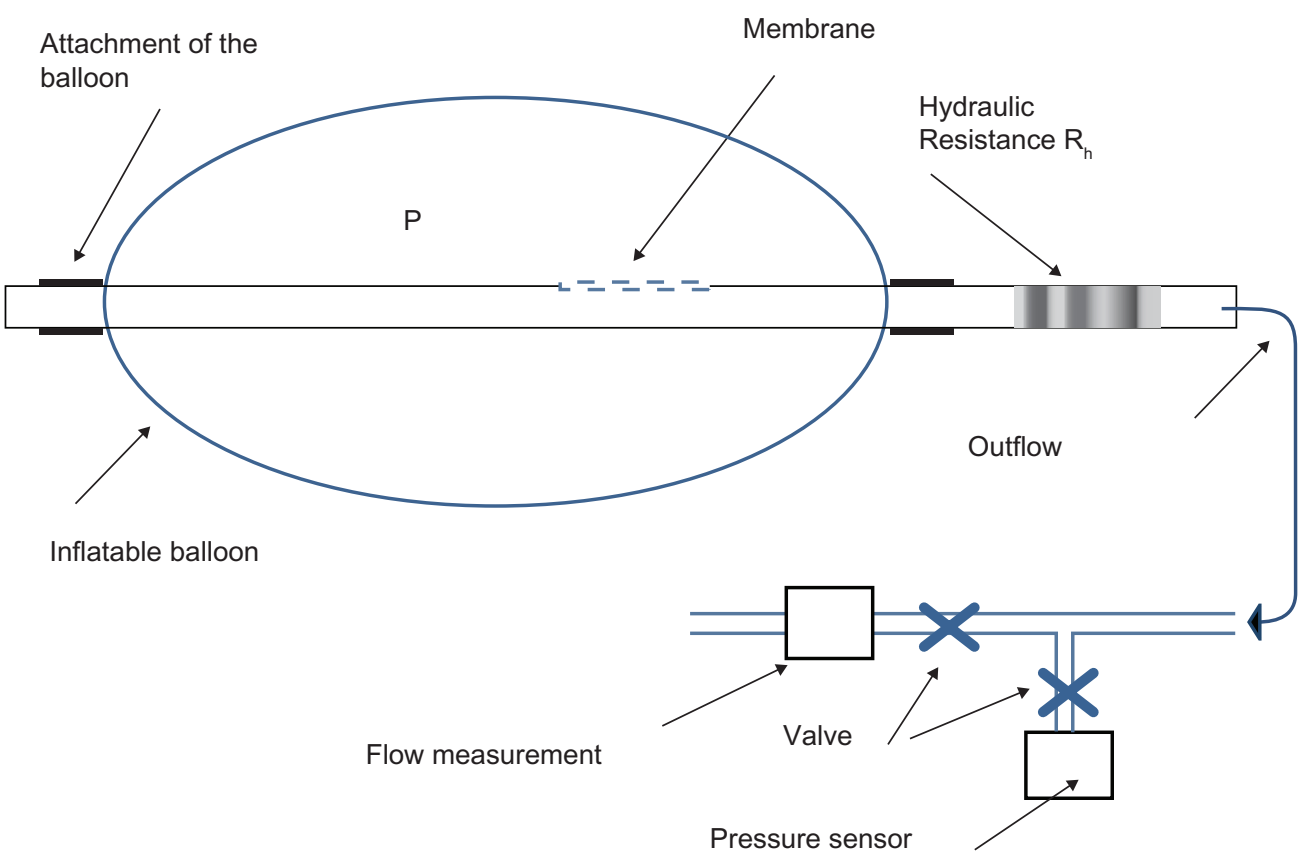

Figure 2 Schematic representation of the experimental setup. 


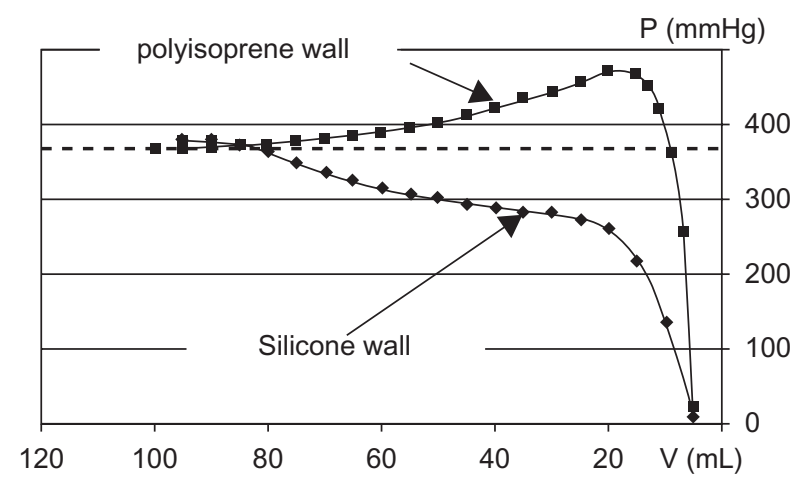

Figure 3 Internal pressure in the reservoirs in $\mathrm{mm} \mathrm{Hg}$ as a function of the remaining volume to be infused.

Figure 3. The nominal internal pressure (the dotted line on the graph) shows desired stability to ensure constant flow rate. The 2 types of elastomer demonstrate different performances. With Pi, P slightly increases before dropping suddenly when the residual volume reaches about $10 \mathrm{~mL}$ (10\% of the fill volume). With $\mathrm{Si}, \mathrm{P}$ decreases constantly and drops suddenly when the residual volume reaches about $20 \mathrm{~mL}$ ( $20 \%$ of the fill volume).

b. Pi and Si reservoirs filled to nominal volume, claimed flow rate of $200 \mathrm{~mL} /$ hour, $\mathrm{P}=380 \mathrm{~mm} \mathrm{Hg}$, high $\mathrm{P}_{\mathrm{v}}$ (44 mm Hg). When increasing $\mathrm{P}_{\mathrm{v}}$, without changing $\mathrm{P}, \mathrm{Q}$ decreases and, therefore, the time to infuse the full volume increases. Perfusion kinetics, shown in Figures $4 \mathrm{a}, 4 \mathrm{~b}$, $5 \mathrm{a}$ and $5 \mathrm{~b}$, is similar for both $\mathrm{P}_{\mathrm{v}}$ values. Dotted lines in Figures $4 \mathrm{~b}$ and $5 \mathrm{~b}$ indicate the claimed flow rate and infusion duration.

c. Pi and Si reservoirs filled to nominal volume, claimed flow rate of $200 \mathrm{~mL} /$ hour, $\mathrm{P}=380 \mathrm{~mm} \mathrm{Hg}$, low $\mathrm{P}_{\mathrm{v}}$ ( $3 \mathrm{mmHg}$ ), time delay of 12 hours. When a time delay of 12 hours between filling and infusion is introduced, the mechanical performances are impacted as shown in

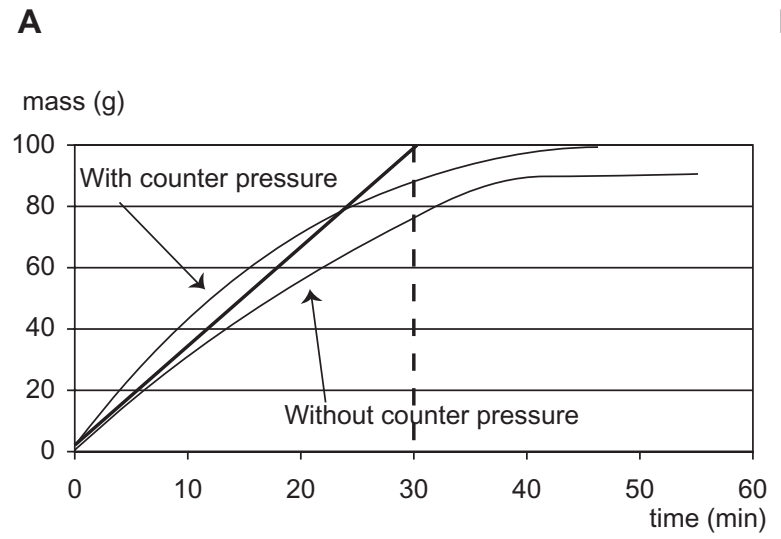

Figures $6 \mathrm{a}$ and $6 \mathrm{~b}$. With Pi, the flow rate (“delayed flow”) decreases slightly $(\approx 10 \%)$ and the infusion duration increases proportionally $(\approx 10 \%)$. However, perfusion kinetics remains similar. This could be due to a fatigue effect in the elastomer. With Si, perfusion kinetics differs significantly between delayed and immediate use. Si shows a complex response to mechanical stress, which impacts its viscoelastic features.

d. Pi and Si reservoirs filled to nominal volume, claimed flow rate of 10 or $5 \mathrm{~mL} /$ hour, $\mathrm{P}=380 \mathrm{~mm} \mathrm{Hg}$, high $\mathrm{P}_{\mathrm{v}}$ (44 mm Hg). In the case of low flow rate and long infusion time, perfusion kinetics is impacted neither by high $\mathrm{P}_{\mathrm{v}}$ nor by the fill volume of the reservoirs. With Pi, flow rate kinetics is homothetic (Figures $7 \mathrm{a}$ and $7 \mathrm{~b}$ ). With $\mathrm{Si}$, it is significantly different (Figures $8 \mathrm{a}$ and $8 \mathrm{~b}$ ) and the recorded flow rates were lower than the claimed ones.

\section{Discussion}

When using volumetric or syringe-pumps, the flow rate $(\mathrm{Q})$ is set by the operator. The device motor maintains the rate. Pressure $(\mathrm{P})$ is exerted on the reservoir as a function of fluid path resistances $\left(\mathrm{R}_{\mathrm{h}}\right)$. However, to prevent damage to the vascular access device, its increase is limited. When the maximum value is reached, an alarm will ring. In EDs, pressure $(\mathrm{P})$ generated by the elastomer is assumed to be constant. The real flow rate depends on the initial value of its components $\left(\mathrm{P}_{\mathrm{P}} \mathrm{P}_{\mathrm{v}}\right.$ and $\mathrm{R}_{\mathrm{h}}$ ) and on their variations with time. The relationship is linear. Any change will induce a variation of $Q$ and of infusion time of the same order. In other words, a $1 \%$ increase in $\mathrm{R}_{\mathrm{h}}$ or $\mathrm{P}_{\mathrm{v}}$ will slow $\mathrm{Q}$ by $1 \%$ and increase infusion time.

i. Because of the structure of the elastomers, $\mathrm{P}$ is not constant (see Figure 3), so Q is not either. Furthermore, $\mathrm{Si}$ and $\mathrm{Pi}$ exhibit different mechanical performances. Si shows a complex response to physical stress, which is

B

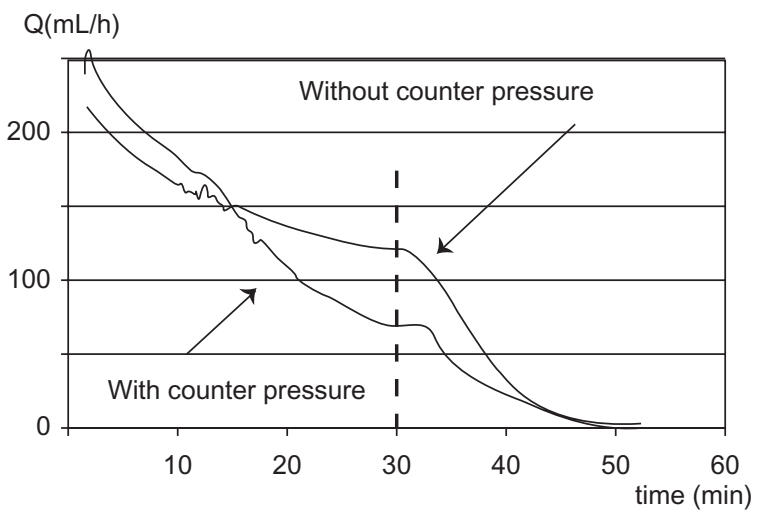

Figure 4 Mass collected (a) and flow rate (b) for $\mathrm{Pv}$ of 3 and $44 \mathrm{~mm} \mathrm{Hg}$, as a function of time for $100 \mathrm{~mL}$ Si reservoirs. The straight bold line in (a) is the ideal time dependence of $P$. 
A

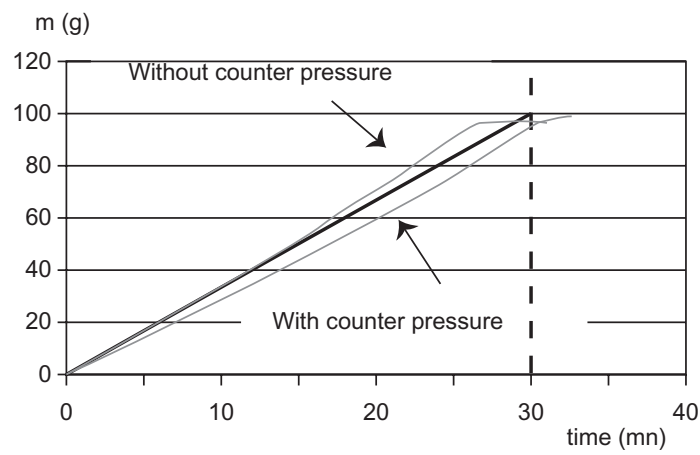

B

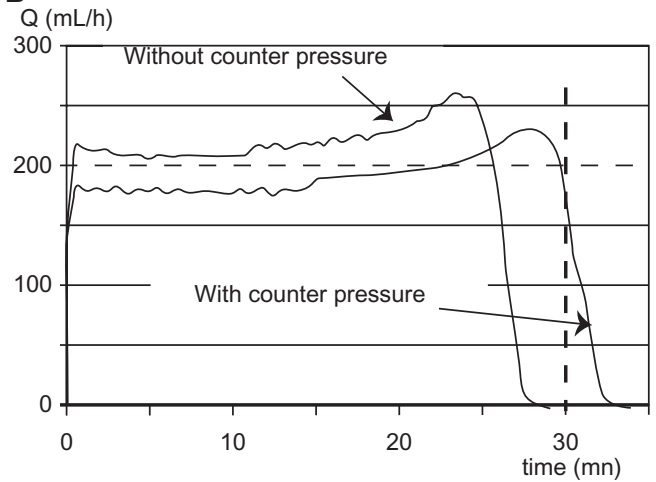

Figure 5 Mass collected (a) and flow (b) for Pv of 3 and $44 \mathrm{~mm} \mathrm{Hg}$, as a function of time for $100 \mathrm{~mL}$ Pi reservoirs. The straight bold line in (a) is the ideal time dependence of P.

A

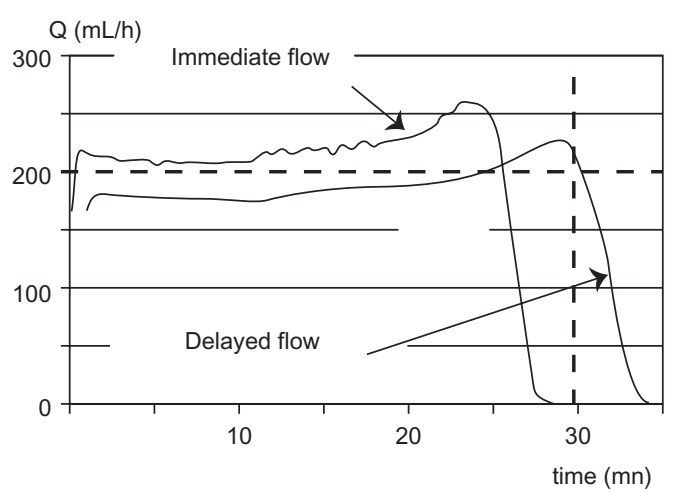

B

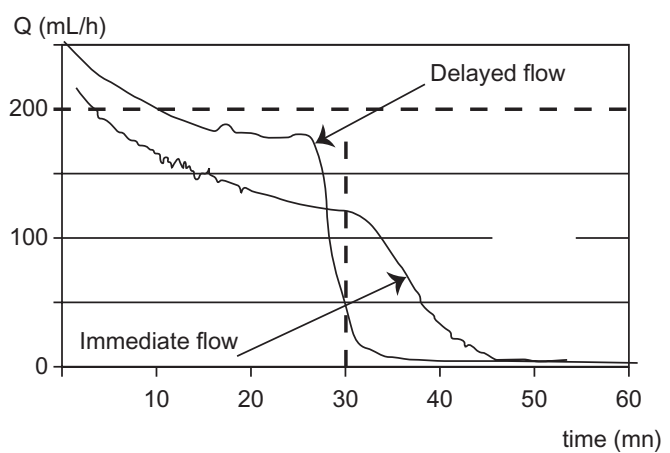

Figure 6 Flow rate as a function of time with ("delayed flow") and without ("immediate flow") a 12 hour time delay for Pi (a) and Si (b) $100 \mathrm{~mL}$ reservoirs.

A

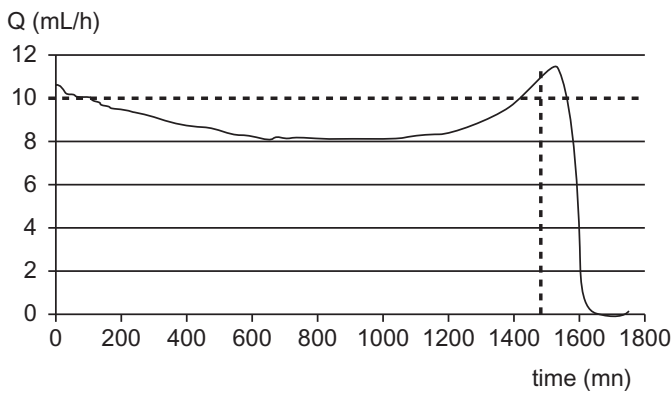

B

$\mathrm{Q}(\mathrm{mL} / \mathrm{h})$

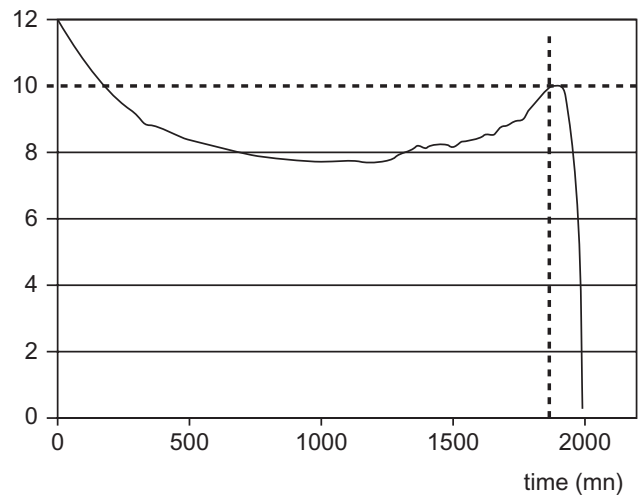

Figure 7 Flow rate as a function of time for a Pi reservoir filled respectively with $240 \mathrm{~mL}$ (a) and $300 \mathrm{~mL}$ (b) both for a $10 \mathrm{~mL} / \mathrm{h}$ claimed flow rate value.

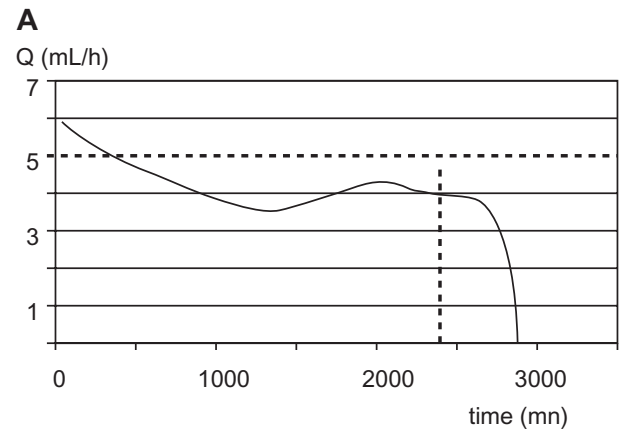

B

$\mathrm{Q}(\mathrm{mL} / \mathrm{h})$

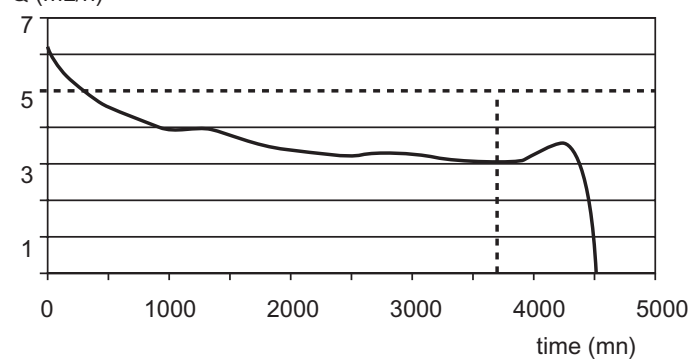

Figure 8 Flow rates as a function of time for a Si reservoir filled respectively with $200 \mathrm{~mL}$ (a) and $300 \mathrm{~mL}$ (b) both for a $5 \mathrm{~mL} / \mathrm{h}$ claimed flow rate value. 


\section{$\mathrm{mPa}$.s}

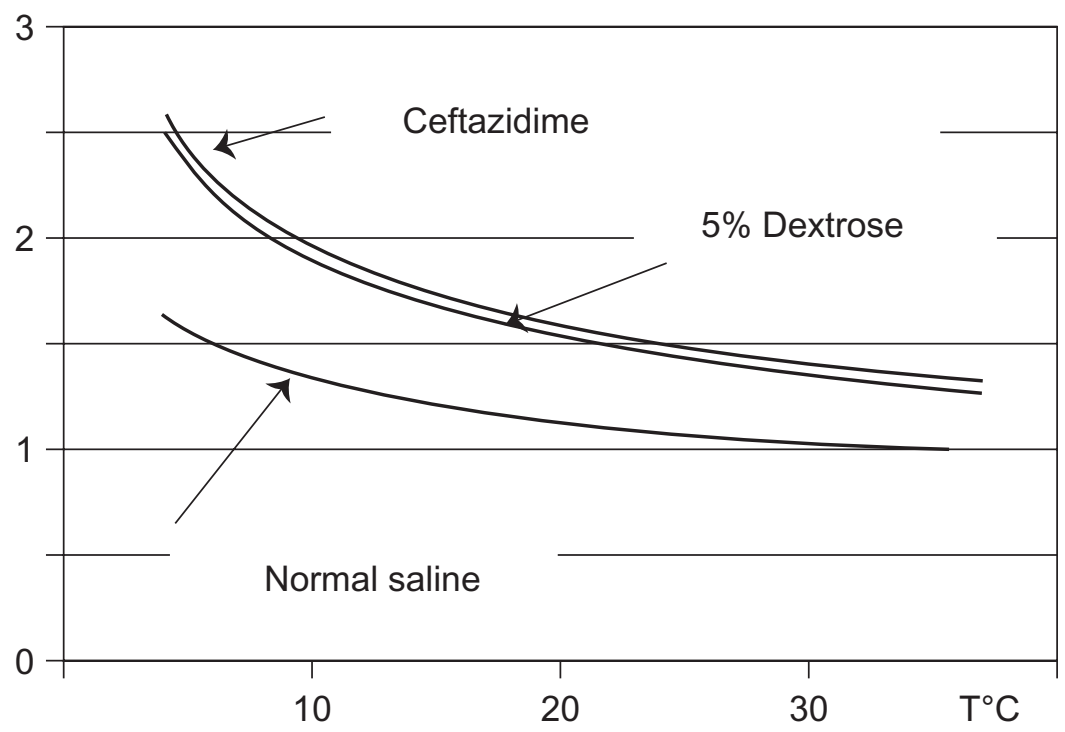

Figure 9 Change of viscosity with temperature of some IV fluids or drugs.

time dependent. Therefore, the hypothesis of constant and stable infusion kinetics is unreasonable. Pi has a much shorter relaxation time, which does not significantly impact infusion kinetics (see Figures 7 and 8).

ii. Moreover, $\mathrm{P}_{\mathrm{v}}$ can dramatically increase under various pathological conditions. As an example, primary and secondary chronic obstructive pulmonary diseases such as cystic fibrosis are associated with coughing fits during which intrathoracic pressure can reach $45 \mathrm{~mm} \mathrm{Hg}$ and sometimes $300 \mathrm{~mm} \mathrm{Hg}^{15}$ for a short time. Their intensity and repetition can lead to blood backflow into the vascular access device lumen $\left(\mathrm{P}_{\mathrm{v}}>\mathrm{P}\right)$, decreasing their patency and further impacting the flow rate.

iii. Other factors can potentially impact the flow rate. One of these is IV fluid viscosity, which not only covers a wide range but also changes with temperature as shown for 2 IV fluids (normal saline, $5 \%$ dextrose) and one IV drug (ceftazidime $4 \mathrm{~g} / 100 \mathrm{~mL}$ ) in Figure 9. Even if the use of EDs to maintain the patency of vascular access devices has been advocated, ${ }^{13}$ they are mainly used to administer IV therapies. In such cases, the dose is prescribed according to patient weight or body surface area among other criteria, including pharmacokinetics (ie, blood concentration) to reach the optimal benefit/ risk ratio. It is clear that a passive device cannot strictly meet this demand because of ineluctable interpersonal variations in addition to mechanical variations, which cannot be preliminarily quantified. Likewise, one should keep in mind that the differences between the prescribed flow rate parameters (ie, $\mathrm{mg} / \mathrm{kg} /$ hour) and the effectively infused ones, may lead to toxicity in the case of overdosing or to a loss of effectiveness or potential resistance (underdosing). Therefore, EDs are suitable for some IV therapies, but not when the flow rate must remain stable at the claimed value. ${ }^{14}$

iv. Last, but not least, a time delay between filling and infusion times also impacts the flow rate, as shown in Figure 6. This parameter should also be taken into account.

\section{Conclusion}

The experimental conditions were chosen to test the mechanical performances of the 2 commonly used elastomers (Si and $\mathrm{Pi}$ ) excluding other variables that also impact flow rate (including fluid viscosity, resistance of infusion tubing and links, height difference between the ED and the catheter, among others). Si shows a complex response to physical stress which is time dependent. Therefore, the hypothesis of constant and stable infusion kinetics with this material is unreasonable. On the other hand, the relaxation time of $\mathrm{Pi}$ is much shorter and does not significantly impact infusion kinetics.

This raises questions about the criteria for choice and optimal conditions of use of these elastomers, keeping in mind that:

- preference should be given to EDs using polyisoprene (Pi).

- available EDs fulfill ISO specifications.

- the flow rates claimed by the manufacturers are an indication valid only under given stable conditions which exclude various parameters. 
- there is little information about the practical, clinical and pharmacological consequences of the various ways to prepare, store and use these devices.

Further work is planned to compare various brands and types of EDs to quantify their performances and their limits.

\section{Disclosure}

The authors report no conflicts of interest in this work.

\section{References}

1. Onkelinx L. Liste des diffuseurs remboursés par la sécurité sociale. Le Moniteur Belge. (Belgisch Staatsblad) 2nd Ed. Arrêté Royal; 2009:68347-68350.

2. Geubelle B, Duvivier F. Préparation des chimiothérapies anticancéreuses. 3ème réunion du BOPP (Belgian Oncology Pharmacy Practitioners), 2010 Nov 30-Dec 2; Grand Gigard, Belgique.

3. ISO 28620. Medical devices - Non-electrically driven portable infusion devices. 2010.

4. Remerand F, Vuitton AS, Palud M, et al. Elastomeric pump reliability in postoperative regional anesthesia: a survey of 430 consecutive devices. Anesth Analg. 2008;107(6):2079-2084.

5. Capdevila X, Macaire P, Aknin P, Dadure C, Bernard N, Lopez S. Patient controlled perineural analgesia after ambulatory orthopedic surgery; a comparison of electronic versus elastomeric pumps. Anesth Analg. 2003;96(2):414-417.

6. Gruwez B, Lecante V, Dauphin A. Assessment of three portable infusion devices used for cytotoxic drugs. J Pharm Clin. 2002;21(3):199-203.
7. Macaire P, Gaertner E, Capdevila X. Continuous post-operative regional analgesia at home. Minerva Anestesiol. 2001;67(9 Suppl 1): 109-116.

8. Bernard L, El-Hajj, Pron B, et al. Outpatient parenteral antimicrobial therapy (OPAT) for the treatment of osteomyelitis: evaluation of efficacy, tolerance and cost. J Clin Pharm Ther. 2001;26(6): $445-451$.

9. Di Lauro V, Spazzapan S, Lombardi D, et al. Fourteen-day infusion of ifosfamide in the management of advanced breast cancer refractory to protracted continuous infusion of 5-fluorouracil. Tumori. 2001;87(1): $27-29$.

10. Lombardi D, Magri MD, Crivellari D, et al. Combination chemotherapy with navelbine and continuous infusion of 5-fluorouracil in metastatic, chemotherapy refractory breast cancer. Ann Onco. 2000;11(8):1041-1043.

11. Capes DF, Asiimwe D. Performance of selected flow restricting infusion devices. Am J Health Syst Pharm. 1998;55(4):351-359.

12. Thiveaud D, Demazières V, Lafont J. Comparison of the performance of four elastomeric devices. Eur J Hosp Pharm Pract. 2005;11(2): $54-56$.

13. Ackerman M, Maier S, Ing H, Bonnabry P. Evaluation of the design and reliability of three elastomeric and one mechanical infusers. $J$ Oncol Pharm Pract. 2007;13(2):77-84.

14. McCool FD. Global physiology and pathophysiology of cough: ACCP evidence-based clinical practical guidelines. Chest. 2006;129(1 Suppl): $48 \mathrm{~S}-53 \mathrm{~S}$.

15. Heath J, Jones S. Utilization of an elastomeric continuous infusion device to maintain catheter patency. J Intraven Nurs. 2001;24(2): 102-106.
Medical Devices: Evidence and Research

\section{Publish your work in this journal}

Medical Devices: Evidence and Research is an international, peerreviewed, open access journal that focuses on the evidence, technology, research, and expert opinion supporting the use and application of medical devices in the diagnosis, treatment and management of clinical conditions and physiological processes. The identification of novel

\section{Dovepress}

devices and optimal use of existing devices which will lead to improved clinical outcomes and more effective patient management and safety is a key feature. The manuscript management system is completely online and includes a quick and fair peer-review system. Visit http://www. dovepress.com/testimonials.php to read real quotes from authors. 